\title{
What Have We Learnt about BCG Vaccination in the Last 20 Years?
}

\author{
Hazel M. Dockrell* and Steven G. Smith \\ Faculty of Infectious and Tropical Diseases, Department of Immunology and Infection, London School of Hygiene and \\ Tropical Medicine, London, United Kingdom
}

A number of new tuberculosis (TB) vaccines have been or are entering clinical trials, which include genetically modified mycobacteria, mycobacterial antigens delivered by viral vectors, or mycobacterial antigens in adjuvant. Some of these vaccines aim to replace the existing BCG vaccine but others will be given as a boosting vaccine following $B C G$ vaccination given soon after birth. It is clear that the existing $B C G$ vaccines provide incomplete and variable protection against pulmonary TB. This review will discuss what we have learnt over the last 20 years about how the BCG vaccine induces specific and non-specific immunity, what factors influence the immune responses induced by BCG, and progress toward identifying correlates of immunity against TB from BCG vaccination studies. There is still a lot to learn about the BCG vaccine and the insights gained can

OPEN ACCESS

Edited by:

Stefan H. E. Kaufmann, Max Planck Institute for Infection Biology (MPG), Germany

Reviewed by: Brosch Roland, Louis Pasteur University, France Marcel Behr, McGill University, Canada

*Correspondence: Hazel M. Dockrell hazel.dockrell@/shtm.ac.uk

Specialty section: This article was submitted to Vaccines and Molecular Therapeutics, a section of the journal Frontiers in Immunology

Received: 26 June 2017 Accepted: 28 August 2017 Published: 13 September 2017

Citation: Dockrell HM and Smith SG (2017) What Have We Learnt about BCG Vaccination in the Last 20 Years?

Front. Immunol. 8:1134. doi: 10.3389/fimmu.2017.01134 help the development of more protective vaccines.

Keywords: BCG, vaccination, tuberculosis, efficacy, biomarkers, correlates of protection, immune responses, infants

\section{INTRODUCTION}

The BCG vaccine has been used since 1921 to prevent tuberculosis (TB) and is considered to be the world's most widely used vaccine (1). Yet, it is well established that the protective efficacy of BCG varies depending in which geographical location it is administered and we understand very little about why it protects when it does, or why it fails to protect when it does not. This review will survey what we have learnt about BCG over the last 20 years. Although a lot of progress has been made, the past two decades have shown that there is no simple correlate of BCG-induced protection against $\mathrm{TB}$ even though T-cells and IFN $\gamma$ are clearly required.

We still need to understand why BCG gives such variable protection against pulmonary TB in different settings. The BCG vaccine remains critical for the development of new TB vaccines, many of which will be given as a booster vaccine after BCG vaccination, and any factors that affect how BCG works may also impact on these as well as on new genetically modified BCG vaccines or other live mycobacterial vaccines $(2,3)$.

Neonatal BCG provides good protection against disseminated and pulmonary TB disease in young children (4) but variable efficacy against pulmonary TB in adults when given later in life. However, when it does protect, this protection can be long-lived, lasting for up to 15 years in the United Kingdom (5), 30-40 years in Norway (6), and even as long as 50-60 years in Alaska (7). There is also evidence from outbreak settings to support the hypothesis that BCG vaccination can protect against infection, as well as disease; for example, an association has been observed between the presence of a BCG scar and not only less disease but also lower rates of interferon-gamma release assay (IGRA) positivity with relative risks for vaccinated compared with unvaccinated children of 0.61 for infection and 0.51 for disease (8). 
Over the last 20 years most of the world's children have continued to receive BCG immediately after birth or when they are first in contact with health services. In 2005, the United Kingdom, which had previously vaccinated adolescents, switched to a targeted vaccination of infants at higher risk of infection (i.e., with parents or grandparents born in high incidence countries or who live in areas of the United Kingdom where the annual incidence of TB exceeds 40/100,000). Other countries have never given $\mathrm{BCG}$, in order to retain the use of the tuberculin skin test (or the newer IGRA tests) as a means of assessing infection or because the risk of infection is low (9). BCG scars are often the best indication of prior vaccination that is available, but are an imperfect proxy for prior vaccination particularly if infants are vaccinated after birth (10).

Vaccination of young infants can, however, lead to disseminated BCGosis if the infant is HIV-infected (11). For this reason, the Global Committee on Vaccine Safety recommended that BCG vaccine should not be given to infants who were HIV infected. As HIV status is generally not known and as even in areas with higher HIV infection rates, most mothers will be on antiretroviral treatment, and their infants given post exposure prophylaxis, most infants are still being vaccinated without testing. As well as acquired immunodeficiencies, inherited genetic disorders of the immune system also confer susceptibility on infants to disseminated BCG infection following vaccination as well as to childhood TB [reviewed in detail here (12)]. A safer BCG for use in immunocompromised infants would therefore be beneficial.

\section{WHAT HAVE WE LEARNT ABOUT THE CAUSES OF VARIABLE PROTECTION INDUCED BY BCG OVER THE LAST 20 YEARS?}

\section{Pre-Sensitization with Environmental Mycobacteria}

BCG vaccination immediately or shortly after birth provides consistent protection against the disseminated forms of TB in young children $(4,13,14)$, and is very cost effective (15). Neonatal BCG also protects against pulmonary TB in children (4) which contrasts with the variable protection seen against pulmonary TB in adolescents and young adults (16).

BCG vaccination is more protective against pulmonary disease in children and adults at higher latitudes and in those screened for prior sensitization by mycobacteria $(4,17)$. Environmental mycobacterial are often assumed to be the culprits, mycobacteria species that survive in different environmental niches, and colonize humans over time (18). The impact of prior sensitization, as detected by tuberculin skin testing, on the protective efficacy of BCG against pulmonary TB has been shown in a number of settings (4) but not whether this induces masking of the BCG vaccine effect (inducing protection that BCG cannot improve upon) or blocking (inducing pre-existing immune responses that prevent BCG vaccine-induced, protective responses) (19). One reason for limited progress has been the lack of antigens specific for environmental mycobacteria with which to dissect T-cell responses to the different mycobacteria other than tuberculosis or non-tuberculous mycobacteria (NTM; e.g., Mycobacterium avium) (20). Skin test positivity to Mycobacterium tuberculosis purified protein derivative (PPD or tuberculin) increases with age, although indurations $>10 \mathrm{~mm}$ are less frequent in those who are BCG vaccinated (21). It is widely assumed that the effects of environmental mycobacteria or NTM would precede BCG vaccination, perhaps blocking BCG multiplication $(22,23)$; however, this is unlikely for infants vaccinated soon after birth, and too little work has focused on their effects post-BCG. In the mouse model, oral dosing with NTMs following BCG vaccination decreased protection (24).

\section{BCG Strain Variations}

Genetic variability between the different BCG vaccine strains might explain variable protection. The original attenuated Mycobacterium bovis bacille Calmette Guerin was kept in culture for many years before it was properly conserved and seed lots were preserved by lyophilization. It was distributed to different locations worldwide where further culture resulted in what are now known as BCG Russia, Japan, Copenhagen, etc. Improved sequencing methods have shown that further genetic events have occurred in these strains, including additional genetic deletions $(25,26)$. Although some countries have only used one strain of BCG, in others, two or more strains have been used making analysis difficult (27). The different vaccine strains induce varying degrees of T-cell response in in vitro peripheral blood mononuclear cell (PBMC) cultures from those vaccinated with different BCG vaccine strains $(19,28)$. However, to date there has been no evidence that such genetic variation between strains accounts for variability in efficacy or that the protection given by a particular BCG vaccine strain is related to the year in which the study was performed (4).

\section{Route of Administration}

BCG vaccine is delivered most often by the intradermal route. It can be given percutaneously by a multi-puncture device rather than intradermally but a large study in South Africa showed both delivery routes were equally protective $(29,30)$. Most data describing the impact of administration route on vaccine efficacy has come from animals. Originally BCG was given orally and studies in guinea pigs have shown that BCG can be as protective and with less pathology induced post-infection if given BCG is given orally (31). Giving both a BCG prime and an MVA85A boost to mice intranasally induced much more effective protection than seen using other routes of immunization (32), and more recently there is renewed interest in the mucosal route of vaccination (33). In rhesus macaques, improved BCG-induced protection was observed when the vaccine was administered endobronchially into the lungs when compared with parenteral vaccination (34).

There is also a body of data on the effect of administration route on the quantity and quality of the immune response induced. Percutaneous and intradermal routes induced similar immunogenicity in a study in South Korea (35). Giving BCG followed by the ID93 vaccine in GLA adjuvant intranasally induced tissue resident T-helper (Th)-17 T-cells rather than Th-1 T-cell immunity (36) and when BCG itself was given by the mucosal 
route, this resulted in effector memory and resident memory T-cells in the mouse lung (37).

\section{Vaccine Batch Variations}

There have also been questions about viability or growth rate variations in different batches of vaccine, which are only required to have colony forming units between set limits (and thus may also contain varying numbers of dead bacilli). A study in West Africa found that batches of BCG showing slower growth were associated with larger BCG scars, and a higher prevalence of positive PPD skin test responses in the Mantoux skin test (38). Issues of batch or vaccine strain variability are very challenging to study at scale, as the EPI program will ship vaccine from one of several suppliers and thus, as mentioned above, many regions can have used three or more types of vaccine $(9,27)$, as well as different batches of the same vaccine strain.

\section{Global Differences in Non-Specific Protection?}

There has been interest in the benefits of administering BCG for reasons other than as a vaccine against TB for many years. For example, BCG vaccine can be instilled into the bladder where it is an effective immunotherapy against non-muscle invasive bladder cancer $(39,40)$. BCG vaccination is also associated with reduced rates of asthma but despite a number of observational studies, analyzed in two meta-analyses $(41,42)$, there have only been two randomized clinical trials using neonatal BCG vaccination and only one trial showed some beneficial effect $(43,44)$.

Studies in West Africa have indicated that BCG vaccination may have beneficial effects on all-cause mortality in infants, although the effects were most marked in low birth weight infants (45). Until recently, these effects had not been examined in infants in higher income or latitude settings, so there was a lot of interest in a study in Copenhagen that hypothesized that giving BCG at birth to Danish infants would reduce the number of somatic infections. In 2,129 BCG vaccinated and 2,133 unvaccinated controls, BCG vaccination had no effect on all-cause hospitalizations [hazard ratio 1.05 (95\% confidence intervals $0.93-1.18$ )] or on parent-reported infections up to the age of 15 months. There was no difference between outcomes in normal birth weight infants or premature infants in this European setting (46). Some of the previously described non-specific effects of vaccination show sex differences; however, in this Danish study, there was no difference in outcomes by sex (46). Thus, any non-specific effects may be more marked in certain low and middle-income country settings.

\section{DISSECTING IMMUNE RESPONSES TO BCG AT THE CELLULAR AND MOLECULAR LEVEL}

\section{Early Events following Vaccination}

BCG is usually administered by intradermal injection. It has been possible, in animals, to investigate the vaccination site tissue for rapid innate immune responses induced by the array of pathogen-associated molecular patterns BCG is endowed with. These are largely components of the mycobacterial cell wall such as peptidoglycans, arabinogalactan, and mycolic acids that interact with Toll-like receptors (47) and other pattern recognition receptors such as complement receptor and mannose receptor as reviewed recently (48). The immediate response is characterized by inflammatory cytokines in BCG "lesions," including IL-1 $\beta$, TNF $\alpha$, MCP-1, and IL-8, as demonstrated in rabbits. A biphasic pattern of expression indicated that the source of the cytokines is local resident innate cells (days 1-3) followed later by infiltrating mononuclear cells (day 9) (49). Although most studies of the immune response to BCG in humans focus on peripheral blood, punch biopsies at the vaccination site have revealed that live BCG persists until at least 4 weeks post-vaccination in previously unvaccinated adults. The cellular infiltrate at the vaccination site, as revealed by suction blister analysis included lymphocytes $(\mathrm{CD} 3+)$ and monocytes (CD14+) but predominantly comprised CD15+ neutrophils (50). Interestingly, human blood neutrophils that have recently captured BCG mycobacteria in vitro have been shown to cooperate with dendritic cells to enhance antigenspecific T-cell responses (51). Despite the chronic nature of intracellular mycobacterial infections, neutrophils are also present in the immune response in human TB. Gene expression signatures associated with neutrophils were found in TB disease (52) and in the lungs of patients with $\mathrm{TB}$, many neutrophils containing M. tuberculosis are present (53).

BCG lacks the es $x$ - 1 locus which, although providing sufficient attenuation compared with M. bovis or M. tuberculosis to allow its use as a vaccine, prevents phagosomal rupture, cytosolic contact, and host cell death following uptake by phagocytic antigen presenting cells (54). As such, there are a host of cytosolic immune detection systems that are underused by the vaccine but which may represent pathways for the induction of more potently protective immune responses (54). Clearly, in the case of M. tuberculosis, some of these responses are responsible for enhanced virulence via increased inflammation, granuloma formation, and damage to lung structure and function however there appears to be an $e s x$-related balance to be struck between pathogenicity and immunity. Recombinant BCG expressing ESX-1 from M. marinum had much reduced virulence in immunocompromised mice when compared with M. tuberculosis itself or BCG expressing ESX-1 from $M$. tuberculosis however immune responses and protection against $M$. tuberculosis challenge were improved when compared with BCG (55). Interestingly for the design of new vaccines for TB, the ESAT-6 related immune responses that are important for the control of $M$. tuberculosis rely, at least in part, on antigen-non-specific, IFN $\gamma$-producing CD8+ T-cells, and natural killer cells that are induced via the NLRP3-inflammasome-IL-18 pathway (56).

\section{Adaptive Immune Responses to BCG}

The primary mechanism of action of BCG-induced protection against TB has long been thought to be Th- 1 cell mediated and although the last 20 years have provided clues to the involvement of other effector mechanisms, the Th-1 paradigm remains in place. Resident dendritic cells travel to local lymph nodes bearing antigen/live BCG and activate antigen-specific CD4+ T-cells in the presence of type 1 polarizing cytokines such as IL-12 and IL-18. IFN $\gamma$-secreting T-cells therefore represent the 
canonical immune response to BCG vaccination (57). Despite robust Th-1 responses in adults following BCG, our understanding of the newborn immune system dictated that an equivalent response to BCG would be unexpected in infants who demonstrate a marked bias toward regulatory and Th-2 response in their natural reaction to microbial challenge. Surprisingly, BCG also proved to be a potent inducer of Th-1 responses in infants (58). The hypothesis that delaying BCG vaccination of infants might circumvent some of the more profound regulatory effects of the newborn immune response and lead to improved type 1 immunity has come in for some scrutiny, however study results have been mixed (see below).

The antigen specificity of BCG-induced T-cells is broad, reflecting the plethora of mycobacterial antigens possessed by BCG which are presented to the immune system (59). Dendritic cells that have collected BCG antigens have the ability to cross-present antigen and BCG-specific CD8+ T-cells are detectable following BCG stimulation of PBMC from BCG-vaccinated donors in vitro $(60,61)$. Improving this component of the BCG-induced vaccine response is one of several approaches being taken to enhance the immunogenicity of BCG and develop a better TB vaccine. One strategy has been the insertion of the Listeriolysin gene designed to facilitate access of BCG antigen to the endogenous antigen processing pathway (62); the BCG $\Delta$ ureC:hly vaccine is more immunogenic in mice than parental BCG and induces Th- 1 and IL-17-producing T-cells in man $(63,64)$. However, development of a recombinant $\mathrm{BCG}$ with a mutant Perfringolysin gene overexpressing Ag85A, Ag85B, and Rv3407 has been discontinued as varicella zoster virus was reactivated in $2 / 8$ vaccinees, although the vaccine was immunogenic and induced anti-mycobacterial activity in man (65). Another approach is the use of adenovirus vectors rather than MVA to deliver $M$. tuberculosis antigens following BCG vaccination in a prime-boost regimen, as adenovirus vectors induce a more mixed CD4 and CD8 T-cell activation than MVA which is better at inducing CD4 T-cell responses (66).

One of the most prominent developments in the field of immunology in the last 20 years has been the rise of the Th-17 cell, initially identified in the context of autoimmune disease. Th-17 cell polarization is brought about by the activation of CD4+ T-cells in the presence of TGF $\beta$ and IL- 6 and the Th-17 population is characterized by the expression of IL-17 and IL-22. Th-17 cells contribute to the granulomatous response to Mtb infection (67) and they are important for immune protection against more virulent, clinical isolates of $M$. tuberculosis (68). Th-17 cells were responsible for enhanced vaccine-induced protection against Mtb challenge in a mouse model $(69,70)$ and they are often taken as a sign of improved immunogenicity in pre-clinical models of novel TB vaccines. For example, the recombinant BCG vaccine BCG $\Delta$ ureC:hly, which induces increased protection compared with parental BCG in mice, induces increased numbers of IL-17 producing helper T-cells (63), with some increase in CD8 T-cells producing IL-17 in human vaccinees (64). BCG is not considered a potent inducer of Th-17 cells. Our group detected IL-17+ CD4+ T-cells following infant BCG vaccination in the United Kingdom but at much lower frequencies than polyfunctional Th-1 cells (71). One explanation for poor Th-17 responses to BCG may be the strain's lack of the RD1 region as discussed above.
The RD1-encoded ESAT-6 protein, which is absent in BCG, is a potent inducer of Th-17 cells which are activated following interactions between ESAT-6 and TLR-2. Improved protective efficacy is seen when BCG is complemented with the ESAT-6 containing RD1 region; and enhanced Th-17 responses appear to be a component of this protection (72) as do antigen non-specific $\mathrm{CD} 8+$ and natural killer cells (see above).

$\mathrm{B}$-cell and antibody responses in the context of TB have not been studied to the extent of their T-cell counterparts due to what may turn out to be an under-appreciation of their importance. Recent evidence suggests a role for functionally distinct antibody responses in latent $\mathrm{TB}$ infection $(73,74)$ and antibody and memory B-cell responses in BCG-vaccinated adults have been demonstrated $(75,76)$ and may correlate with a reduced risk of TB disease in infants $(77,78)$.

Despite evidence for longevity in the protective efficacy of BCG in some settings, this protection has yet to be attributed to a defined population of memory immune cells. It is difficult in humans to differentiate mycobacteria-specific, long-lived memory cells that are present because of an historic BCG vaccination from responses that are constantly re-stimulated by exposure to environmental mycobacteria. This is easier to study in animal models where exposure to mycobacteria is more easily controlled. In pre-clinical studies of the recombinant BCG vaccine candidate BCG $\Delta$ ureC:hly in mice, there was an association between vaccine-induced protection and CXCR5+ CCR7+ central memory CD4+ T-cells (79). Also, in mice, the quality of the $\mathrm{T}$-cell response to vaccination was reliant upon the persistence of live BCG. Once drug-sensitive BCG bacteria were removed by drug treatment of mice, there was a reduction in antigen-specific $\mathrm{T}$ effector cells, and a reduction in protection (80). In man, BCG is still present in vaccination sites at 1 month after vaccination (50) but data on its longer-term survival are limited. Although there have been case reports of longer-term survival of BCG [i.e., where an HIV-infected individual developed disseminated BCG 30 years after vaccination (81)], disseminated BCG infections have not increased dramatically in countries where HIV infection is more prevalent, suggesting that in most cases BCG does not survive long-term in vaccinees.

\section{BCG-Induced Trained Innate Immunity}

Although interactions between the BCG vaccine and innate immune system receptors such as complement receptor-3 and TLRs 2 and 4 were previously known $(82,83)$, a more recent discovery is the ability of BCG to bestow a type of immunological memory on innate cells, so-called trained innate immunity $(84,85)$. Mediated by NOD2 receptor signaling and epigenetic modification of macrophages, the phenomenon is characterized by an enhanced ability of macrophages to produce cytokines such as TNF $\alpha$ and IL-6 in response to unrelated microorganisms and TLR ligands following BCG vaccination. Natural killer cells have also been demonstrated to contribute to the trained innate effect both in humans and in mice (86). Trained innate cells alter their metabolism, switching from oxidative phosphorylation to aerobic glycolysis (87). Trained immunity is reduced if monocytes from controls are stimulated with irradiated BCG bacilli rather than live BCG (88). Trained innate immunity is clearly a 
prime candidate mechanism to explain the non-specific protective effects of BCG described above. To this end, our group and others have investigated whether BCG vaccination of infants has the same effect on the innate immune response. Jensen et al. in a cohort of West African infants and our group in United Kingdom infants both showed evidence of enhanced innate responses to non-specific stimuli following infant BCG vaccination $(89,90)$.

\section{FACTORS THAT AFFECT BCG-INDUCED IMMUNE RESPONSES}

\section{Vaccination Setting}

As noted above BCG vaccination is less effective against pulmonary $\mathrm{TB}$ in some settings. This phenomenon has been explored using immunological analysis, which confirmed that $>80 \%$ of United Kingdom adolescents did not make an IFN $\gamma$ response to PPD in diluted whole blood cultures before vaccination, whereas over $60 \%$ of Malawian adolescents and young adults did; 12 months post-vaccination there was still marked immunological memory present in most of the United Kingdom vaccinees whereas the Malawian vaccinees did not show a vaccine-induced enhancement of their responses (91). Less expected was the finding that Malawian infants, presumed to be immunologically naïve when vaccinated, also made lower IFN $\gamma$ responses than United Kingdom infants (92) with reduced Th- 1 and increased Th-2 cytokine responses (93). In the United Kingdom, BCGvaccinated infants show increased BCG growth inhibition compared with unvaccinated infants (71); similar studies have not yet been reported for African infants. Again, there are other reports where growth inhibition is not associated with BCG vaccination, or with protection. Although BCG-induced immunity can be long-lived, there was no association between childhood $B C G$ vaccination and mycobacterial growth inhibition in human bronchoaleolar lavage cells from TB contacts as assessed by colony counts (94). In a study of BCG-vaccinated South African infants, tested at 4-6 months of age, there was no significant association between growth inhibition of BCG and subsequent development of disease (77).

A number of other explanations have been suggested for varying immunogenicity and protective efficacy of the BCG vaccine. There are clearly factors related to location or setting. There are seasonal influences that determine how $\mathrm{T}$-cell responses are induced or maintained, as shown for IFN $\gamma$ responses in Malawi (92). Varying vaccination schedules may affect immunogenicity, as shown in some studies where, when BCG vaccine was given with oral polio vaccine (OPV) in Guinea Bissau, IFN $\gamma$, and IL-5 responses to PPD were reduced (95); however, any such immunosuppressive effects resulting from oral live polio vaccination should now reduce as OPV is replaced with inactivated polio vaccine.

\section{Maternal Factors}

In some of these settings, many mothers will be infected with latent $\mathrm{TB}$, and this could lead to either in utero sensitization or tolerization to mycobacterial antigens. However, so far LTBI in mothers has only been shown to have a transient effect on responses to mycobacterial antigens in their infants $(96,97)$. Maternal BCG scar was associated with stronger proinflammatory cytokine responses to innate stimuli in infant cord blood, but not to stronger responses in the mothers themselves (98). Other maternal infections may also modulate BCG-induced immunity. Although infants will not acquire helminth infections until well after BCG vaccination, in LMIC many of their mothers will carry helminth infections. There was no clear association of maternal helminth infection with the infants immune responses to vaccination (99) and treating pregnant women in the second or third trimester with albendazole, praziquantel, or both did not affect infant responses to BCG, tetanus, or measles vaccination (100). Co-infections in the infants themselves could also modulate immunity. Cytomegalovirus infection is acquired early in life by most infants in Africa and has a profound effect on the immune system (101-103). Other factors could include nutrition, genetics, and season of birth $(104,105)$.

\section{Delayed BCG Vaccination}

Many infants do not receive BCG vaccination immediately after birth, and delays in vaccination might improve immunity, due to maturation of the immune system, which is skewed toward Th-2 T-cell immune responses at birth. However, delaying BCG vaccination has shown less consistent effects on BCG-induced immunogenicity than might have been expected (58, 106-110). Partly this lack of consensus results from variations in the approaches taken by different studies, including the age until which vaccination is delayed, the time points post-vaccination at which blood samples are obtained and analyzed and the range of assays used and immunological functions investigated. Delayed BCG may circumvent the risks associated with at birth vaccination of HIVexposed infants. Tchakoute et al. reported that immune responses in HIV-exposed, uninfected infants vaccinated at 8 weeks of age were at least as robust as those in infants vaccinated at birth and in some respects (enhanced CD4 T-cell IFN $\gamma$ responses and increase cytokine functionality in CD4 and CD8 T-cells) delayed vaccination was better (110). Kagina et al. demonstrated better T-cell cytokine responses (including polyfunctional CD4 T-cells) at 1 year in infants where BCG was delayed to 10 weeks of age. The differences detectable at an earlier time point of 10 weeks postvaccination were more modest which agrees with the findings of Ritz et al. who conducted a similar study $(107,109)$.

In contrast to the studies mentioned above in which delaying BCG was either not different or in some cases better than vaccination at birth, two further studies reported that immune responses were enhanced in infants who received BCG at birth compared with those in which it was delayed. In the Gambia, Th-1 and Th-17 responses measured 4.5 months after vaccination were reduced when BCG was delayed to 4.5 months (approximately 19 weeks of age) however the differences became less apparent when samples were obtained later, at 9 months of age (106). In contrast Lutwama et al. found that at 9 months of age it was still possible to detect better CD4 and CD8 T-cell cytokine responses in infants vaccinated at birth compared with those vaccinated at 6 weeks of age (108). In addition to the variables mentioned above, the different settings of all these studies should be noted. With the exception of the study by Ritz 
et al., performed in Australia (109), most of these studies were performed in Africa, although they were located in different settings; some of which (Uganda and the Gambia) were more equatorial than others (South Africa). The same factors that determine the geographical variation in BCG efficacy may also account for differences in the effect of delayed vaccination.

\section{TOWARD CORRELATES OF PROTECTION}

\section{T-Cell and B-Cell Immune Responses as Correlates of Protection}

Although most of these studies have investigated immunogenicity rather than protection, a large study based in South Africa that recruited 5,726 BCG-vaccinated infants and followed them for 2 years, has enabled correlates of risk of disease to be investigated more directly. In this cohort, the proportion of polyfunctional T-cells in BCG stimulated cultures was not associated with reduced risk of developing TB disease (111). Despite comprehensive analyses using gene expression, correlates of risk could not be identified. The protected and unprotected infants showed marked heterogeneity in gene expression patterns, with distinct subsets in both protected and unprotected groups with higher or lower monocyte:lymphocyte ratios and myeloid or lymphoid cell activation (112) (see below). In the only other BCG-vaccinated infant cohort followed for protection against the development of disease, infants from the MVA85A vaccine trial in which the MVA85A vaccination following BCG had not induced significant efficacy (113) were assessed for biosignatures associated with protection or progression. T-cell activation (CD4 T-cells expressing HLA DR) was associated with increased risk of progression to disease, but BCG-induced IFN $\gamma$ producing T-cells were associated with reduced risk of TB (77).

Perhaps as a response to the lack of confirmed T-cell correlates of protection induced by BCG vaccination, there is renewed interest in B-cell immunity in $\mathrm{TB}$, which as noted above has been under-studied. Although antibodies have not provided useful diagnostic tests for TB, expression of B-cell-associated genes are modulated during TB treatment (114) and the frequencies of plasmablasts are increased in those with active TB disease compared with healthy community controls, and community controls with evidence of latent TB infection have higher numbers of both plasmablasts and memory B cells (78). Memory B cells specific for PPD were higher in BCG-vaccinated adult donors than unvaccinated subjects, even from individuals vaccinated 13-45 years earlier (75). It is therefore interesting that in infants from the MVA vaccine trial higher concentrations of IgG antibodies to Ag85 at 5-7 months of age were associated with a reduced risk of subsequent TB (77).

\section{Unbiased Functional Assays of BCG-Induced Protection: Mycobacterial Growth Inhibition}

Functional assays that do not rely on prior knowledge of specific immune correlates of protection have been of interest for some time. Such assays can potentially indicate vaccine-induced protection in easily accessible samples (e.g., whole blood or PBMC) and are unbiased in the sense that they do not focus on any given immune component. Early interest in mycobacterial growth inhibition as a surrogate marker of protection involved the in vitro expansion of lymphocytes with relevant antigens prior to incubation with BCG-infected monocytes. PBMC previously stimulated with mycobacterial whole cell lysate or live BCG induced infected monocytes to control the growth of BCG better as did previous BCG vaccination of donors themselves (115). In another study using an assay that did not rely on in vitro stimulation of PBMC, ex vivo whole blood or fresh PBMC from adults who were recently BCG vaccinated (either primary vaccination or re-vaccination) were incubated with live BCG and growth inhibition determined by Bactec MGIT analysis. The study reported that PBMC from adults who had received primary BCG did control mycobacterial growth better ex vivo than unvaccinated controls (116). In a study of infants vaccinated in early life (at approximately 7 weeks of age), our group demonstrated better PBMC-mediated growth inhibition of BCG in vaccinated infants compared with unvaccinated controls 3 months after vaccination, although the effect had waned by 12 months (71). Despite these positive data supporting the use of mycobacterial growth inhibition as a surrogate marker of vaccine-induced protection, it should be noted that, as with vaccine-induced T-cell responses, growth inhibition was not associated with reduced risk of TB disease in BCG-vaccinated South African infants (77). The concept of mycobacterial growth inhibition has been taken a step further with human challenge models whereby protection is assessed following the administration of an in vivo mycobacterial challenge, usually an intradermal inoculation of live BCG $(117,118)$. Such an approach has allowed the association of in vivo control of live BCG with patterns of gene expression and cellular immune responses (119).

\section{Variable Profiles of Response to BCG Vaccination: Hampering the Search for Correlates of Protection?}

As discussed above, population differences exist in adult and infant immune response to BCG (91-93) however, even within populations, marked heterogeneity in the host response to BCG vaccination has been observed. South African infants who received BCG clustered into two groups of responders that displayed distinct myeloid or lymphoid activation patterns of gene expression (112). Furthermore, Boer and colleagues found that young adults receiving primary BCG vaccination responded in a surprisingly dichotomous manner. Either broadly proimflammatory responses with local reactogenicity and induction of polyfunctional CD4 T-cells or responses characterized by mild local inflammation, poor cytokine, and polyfunctional CD4 $\mathrm{T}$-cell induction and a predominance of regulatory CD8 T-cells were detected (120).

Although there is opportunity in the fact that BCG vaccination demonstrates protective efficacy in infants and in adults in some geographical locations, there are clearly some host-related factors that modify immune responses to BCG and give rise to significant heterogeneity. Until we understand these factors better and take them into account, it will be difficult to identify broadly relevant correlates of protection in BCG-vaccinated cohorts. 


\section{CONCLUSION}

Although there has been much progress over the last 20 years, we are still unable to identify BCG-induced correlates of protection in vaccinated infants. This remains a priority area for further research, as it is possible that the development of effective boosting $\mathrm{TB}$ vaccines could be abandoned simply because we have yet to discover the essential aspect of BCG-induced immunity to TB that should be boosted. Similarly, a better understanding of BCG-induced correlates of protection will help novel, live mycobacterial vaccines avoid the pitfalls that have caused BCG to fail in certain settings. To date, the search for BCG-induced correlates has been far too simplistic. However, the advent of more detailed immune and memory cell phenotyping obtained using mass cytometry (121) and the availability of more gene expression datasets in recent times is providing an increasingly

\section{REFERENCES}

1. Dye C. Making wider use of the world's most widely used vaccine: bacille Calmette-Guerin revaccination reconsidered. JR Soc Interface (2013) 10:20130365. doi:10.1098/rsif.2013.0365

2. Fletcher HA. Sleeping beauty and the story of the bacille Calmette-Guérin vaccine. MBio (2016) 7:e01370-16. doi:10.1128/mBio.01370-16

3. Scriba TJ, Kaufmann SHE, Henri Lambert P, Sanicas M, Martin C, Neyrolles O. Vaccination against tuberculosis with whole-cell mycobacterial vaccines. J Infect Dis (2016) 214:659-64. doi:10.1093/infdis/jiw228

4. Mangtani P, Abubakar I, Ariti C, Beynon R, Pimpin L, Fine PEM, et al. Protection by BCG vaccine against tuberculosis: a systematic review of randomized controlled trials. Clin Infect Dis (2014) 58:470-80. doi:10.1093/ $\mathrm{cid} / \mathrm{cit} 790$

5. Sterne JA, Rodrigues LC, Guedes IN. Does the efficacy of BCG decline with time since vaccination? Int J Tuberc Lung Dis (1998) 2:200-7.

6. Nguipdop-Djomo P, Heldal E, Rodrigues LC, Abubakar I, Mangtani P. Duration of BCG protection against tuberculosis and change in effectiveness with time since vaccination in Norway: a retrospective populationbased cohort study. Lancet Infect Dis (2016) 16:219-26. doi:10.1016/ S1473-3099(15)00400-4

7. Aronson NE, Santosham M, Comstock GW, Howard RS, Moulton LH, Rhoades ER, et al. Long-term efficacy of BCG vaccine in American Indians and Alaska Natives: a 60-year follow-up study. JAMA (2004) 291:2086-91. doi:10.1001/jama.291.17.2086

8. Eisenhut M, Paranjothy S, Abubakar I, Bracebridge S, Lilley M, Mulla R, et al. BCG vaccination reduces risk of infection with Mycobacterium tuberculosis as detected by gamma interferon release assay. Vaccine (2009) 27:6116-20. doi:10.1016/j.vaccine.2009.08.031

9. Zwerling A, Behr MA, Verma A, Brewer TF, Menzies D, Pai M. The BCG world atlas: a database of global BCG vaccination policies and practices. PLoS Med (2011) 8:e1001012. doi:10.1371/journal.pmed.1001012

10. Floyd S, Pönnighaus JM, Bliss L, Warndorff DK, Kasunga A, Mogha P, et al. BCG scars in northern Malawi: sensitivity and repeatability of scar reading, and factors affecting scar size. Int J Tuberc Lung Dis (2000) 4:1133-42.

11. Hesseling AC, Rabie H, Marais BJ, Manders M, Lips M, Schaaf HS, et al. Bacille Calmette-Guérin vaccine-induced disease in HIV-infected and HIVuninfected children. Clin Infect Dis (2006) 42:548-58. doi:10.1086/499953

12. Boisson-Dupuis S, Bustamante J, El-Baghdadi J, Camcioglu Y, Parvaneh N, Azbaoui El S, et al. Inherited and acquired immunodeficiencies underlying tuberculosis in childhood. Immunol Rev (2015) 264:103-20. doi:10.1111/ imr. 12272

13. Colditz GA, Berkey CS, Mosteller F, Brewer TF, Wilson ME, Burdick E, et al. The efficacy of bacillus Calmette-Guérin vaccination of newborns and infants in the prevention of tuberculosis: meta-analyses of the published literature. Pediatrics (1995) 96:29-35. nuanced picture. Coupled with sophisticated bioinformatic analyses, these new approaches may soon identify the complex biosignatures associated with BCG-induced protection against $\mathrm{TB}$.

\section{AUTHOR CONTRIBUTIONS}

HD and SS wrote, edited, and approved the final version of this article.

\section{FUNDING}

HD and SS are funded by the European Commission within Horizon2020 TBVAC2020 (grant number H2020 PHC-643381) and by the Medical Research Council (project grant number MR/ K019708).

14. Roy A, Eisenhut M, Harris RJ, Rodrigues LC, Sridhar S, Habermann S, et al. Effect of BCG vaccination against Mycobacterium tuberculosis infection in children: systematic review and meta-analysis. BMJ (2014) 349:g4643. doi:10.1136/bmj.g4643

15. Trunz BB, Fine PEM, Dye C. Effect of BCG vaccination on childhood tuberculous meningitis and miliary tuberculosis worldwide: a meta-analysis and assessment of cost-effectiveness. Lancet (2006) 367:1173-80. doi:10.1016/ S0140-6736(06)68507-3

16. Fine PE. Variation in protection by BCG: implications of and for heterologous immunity. Lancet (1995) 346:1339-45. doi:10.1016/S0140-6736(95)92348-9

17. Bjartveit K. Olaf Scheel and Johannes Heimbeck and their work with the BCG vaccine. Tidsskr Nor Laegeforen (2001) 121:1076-81.

18. McShane H. Understanding BCG is the key to improving it. Clin Infect Dis (2014) 58:481-2. doi:10.1093/cid/cit793

19. Andersen P, Doherty TM. The success and failure of BCG-implications for a novel tuberculosis vaccine. Nat Rev Microbiol (2005) 3:656-62. doi:10.1038/ nrmicro1211

20. Checkley AM, Wyllie DH, Scriba TJ, Golubchik T, Hill AVS, Hanekom WA, et al. Identification of antigens specific to non-tuberculous mycobacteria: the Mce family of proteins as a target of T cell immune responses. PLoS One (2011) 6:e26434. doi:10.1371/journal.pone.0026434

21. Crampin AC, Glynn JR, Fine PEM. What has Karonga taught us? Tuberculosis studied over three decades. Int J Tuberc Lung Dis (2009) 13:153-64.

22. Brandt L, Feino Cunha J, Weinreich Olsen A, Chilima B, Hirsch P Appelberg R, et al. Failure of the Mycobacterium bovis BCG vaccine: some species of environmental mycobacteria block multiplication of BCG and induction of protective immunity to tuberculosis. Infect Immun (2002) 70:672-8. doi:10.1128/IAI.70.2.672-678.2002

23. Poyntz HC, Stylianou E, Griffiths KL, Marsay L, Checkley AM, McShane H. Non-tuberculous mycobacteria have diverse effects on BCG efficacy against Mycobacterium tuberculosis. Tuberculosis (Edinb) (2014) 94:226-37. doi:10.1016/j.tube.2013.12.006

24. Flaherty DK, Vesosky B, Beamer GL, Stromberg P, Turner J. Exposure to Mycobacterium avium can modulate established immunity against $\mathrm{Myco}$ bacterium tuberculosis infection generated by Mycobacterium bovis BCG vaccination. J Leukoc Biol (2006) 80:1262-71. doi:10.1189/jlb.0606407

25. Abdallah AM, Hill-Cawthorne GA, Otto TD, Coll F, Guerra-Assunção JA, Gao G, et al. Genomic expression catalogue of a global collection of BCG vaccine strains show evidence for highly diverged metabolic and cell-wall adaptations. Sci Rep (2015) 5:15443. doi:10.1038/srep15443

26. Bottai D, Brosch R. The BCG strain pool: diversity matters. Mol Ther (2016) 24:201-3. doi:10.1038/mt.2016.18

27. Ritz N, Curtis N. Mapping the global use of different BCG vaccine strains. Tuberculosis (Edinb) (2009) 89:248-51. doi:10.1016/j.tube.2009.03.002

28. Ritz N, Dutta B, Donath S, Casalaz D, Connell TG, Tebruegge M, et al. The influence of bacille Calmette-Guerin vaccine strain on the immune response 
against tuberculosis: a randomized trial. Am J Respir Crit Care Med (2012) 185:213-22. doi:10.1164/rccm.201104-0714OC

29. Davids V, Hanekom WA, Mansoor N, Gamieldien H, Gelderbloem SJ, Hawkridge A, et al. The effect of bacille Calmette-Guérin vaccine strain and route of administration on induced immune responses in vaccinated infants. J Infect Dis (2006) 193:531-6. doi:10.1086/499825

30. Hawkridge A, Hatherill M, Little F, Goetz MA, Barker L, Mahomed H, et al. Efficacy of percutaneous versus intradermal BCG in the prevention of tuberculosis in South African infants: randomised trial. BMJ (2008) 337:1275-8. doi:10.1136/bmj.a2052

31. Clark SO, Kelly DLF, Badell E, Castello-Branco LR, Aldwell F, Winter N, et al. Oral delivery of BCG Moreau Rio de Janeiro gives equivalent protection against tuberculosis but with reduced pathology compared to parenteral BCG Danish vaccination. Vaccine (2010) 28:7109-16. doi:10.1016/j.vaccine.2010.07.087

32. Goonetilleke NP, McShane H, Hannan CM, Anderson RJ, Brookes RH, Hill AVS. Enhanced immunogenicity and protective efficacy against Mycobacterium tuberculosis of bacille Calmette-Guérin vaccine using mucosal administration and boosting with a recombinant modified vaccinia virus Ankara. J Immunol (2003) 171:1602-9. doi:10.4049/jimmunol.171.3.1602

33. Manjaly-Thomas Z-R, McShane H. Aerosol immunisation for TB: matching route of vaccination to route of infection. Trans R Soc Trop Med Hyg (2015) 109:175-81. doi:10.1093/trstmh/tru206

34. Verreck FAW, Tchilian EZ, Vervenne RAW, Sombroek CC, Kondova I, Eissen OA, et al. Variable BCG efficacy in rhesus populations: pulmonary BCG provides protection where standard intra-dermal vaccination fails. Tuberculosis (Edinb) (2017) 104:46-57. doi:10.1016/j.tube.2017.02.003

35. Lee H, Cho SN, Kim HJ, Anh YM, Choi JE, Kim CH, et al. Evaluation of cell-mediated immune responses to two BCG vaccination regimes in young children in South Korea. Vaccine (2011) 29:6564-71. doi:10.1016/j. vaccine.2011.07.003

36. Orr MT, Beebe EA, Hudson TE, Argilla D, Huang P-WD, Reese VA, et al. Mucosal delivery switches the response to an adjuvanted tuberculosis vaccine from systemic TH1 to tissue-resident TH17 responses without impacting the protective efficacy. Vaccine (2015) 33:6570-8. doi:10.1016/j.vaccine. 2015.10.115

37. Perdomo C, Zedler U, Kühl AA, Lozza L, Saikali P, Sander LE, et al. Mucosal $B C G$ vaccination induces protective lung-resident memory $\mathrm{T}$ cell populations against tuberculosis. MBio (2016) 7:e01686-16. doi:10.1128/mBio.01686-16

38. Biering-Sørensen S, Jensen KJ, Aamand SH, Blok B, Andersen A, Monteiro I, et al. Variation of growth in the production of the BCG vaccine and the association with the immune response. An observational study within a randomised trial. Vaccine (2015) 33:2056-65. doi:10.1016/j.vaccine. 2015.02.056

39. Alexandroff AB, Nicholson S, Patel PM, Jackson AM. Recent advances in bacillus Calmette-Guerin immunotherapy in bladder cancer. Immunotherapy (2010) 2:551-60. doi:10.2217/imt.10.32

40. Kamat AM, Flaig TW, Grossman HB, Konety B, Lamm D, O'Donnell MA, et al. Expert consensus document: consensus statement on best practice management regarding the use of intravesical immunotherapy with BCG for bladder cancer. Nat Rev Urol (2015) 12:225-35. doi:10.1038/nrurol.2015.58

41. Arnoldussen DL, Linehan M, Sheikh A. BCG vaccination and allergy: a systematic review and meta-analysis. J Allergy Clin Immunol (2011) 127:246-53, 253.e1-21. doi:10.1016/j.jaci.2010.07.039

42. El-Zein M, Parent M-E, Benedetti A, Rousseau M-C. Does BCG vaccination protect against the development of childhood asthma? A systematic review and meta-analysis of epidemiological studies. Int J Epidemiol (2010) 39:469-86. doi:10.1093/ije/dyp307

43. Steenhuis TJ, van Aalderen WMC, Bloksma N, Nijkamp FP, van der Laag J, van Loveren $\mathrm{H}$, et al. Bacille-Calmette-Guerin vaccination and the development of allergic disease in children: a randomized, prospective, single-blind study. Clin Exp Allergy (2008) 38:79-85. doi:10.1111/j.1365-2222.2007.02859.x

44. Thøstesen LM, Stensballe LG, Pihl GT, Kjaergaard J, Birk NM, Nissen TN, et al. Neonatal BCG vaccination has no effect on recurrent wheeze in the first year of life: a randomized clinical trial. J Allergy Clin Immunol (2017). doi:10.1016/j.jaci.2016.12.990

45. Aaby P, Roth A, Ravn H, Napirna BM, Rodrigues A, Lisse IM, et al. Randomized trial of BCG vaccination at birth to low-birth-weight children: beneficial nonspecific effects in the neonatal period? J Infect Dis (2011) 204:245-52. doi:10.1093/infdis/jir240

46. Stensballe LG, Sørup S, Aaby P, Benn CS, Greisen G, Jeppesen DL, et al. BCG vaccination at birth and early childhood hospitalisation: a randomised clinical multicentre trial. Arch Dis Child (2017) 102:224-31. doi:10.1136/ archdischild-2016-310760

47. Tsuji S, Matsumoto M, Takeuchi O, Akira S, Azuma I, Hayashi A, et al. Maturation of human dendritic cells by cell wall skeleton of Mycobacterium bovis bacillus Calmette-Guérin: involvement of toll-like receptors. Infect Immun (2000) 68:6883-90. doi:10.1128/IAI.68.12.6883-6890.2000

48. Moliva JI, Turner J, Torrelles JB. Immune responses to bacillus CalmetteGuérin vaccination: why do they fail to protect against Mycobacterium tuberculosis? Front Immunol (2017) 8:407. doi:10.3389/fimmu.2017.00407

49. Sugisaki K, Dannenberg AM, Abe Y, Tsuruta J, Su WJ, Said W, et al. Nonspecific and immune-specific up-regulation of cytokines in rabbit dermal tuberculous (BCG) lesions. J Leukoc Biol (1998) 63:440-50.

50. Minassian AM, Satti I, Poulton ID, Meyer J, Hill AVS, McShane H. A human challenge model for Mycobacterium tuberculosis using Mycobacterium bovis bacille Calmette-Guerin. J Infect Dis (2012) 205:1035-42. doi:10.1093/infdis/ jis012

51. Morel C, Badell E, Abadie V, Robledo M, Setterblad N, Gluckman JC, et al. Mycobacterium bovis BCG-infected neutrophils and dendritic cells cooperate to induce specific T cell responses in humans and mice. Eur J Immunol (2008) 38:437-47. doi:10.1002/eji.200737905

52. Berry MPR, Graham CM, McNab FW, Xu Z, Bloch SAA, Oni T, et al. An interferon-inducible neutrophil-driven blood transcriptional signature in human tuberculosis. Nature (2010) 466:973-7. doi:10.1038/nature09247

53. Eum S-Y, Kong J-H, Hong M-S, Lee Y-J, Kim J-H, Hwang S-H, et al. Neutrophils are the predominant infected phagocytic cells in the airways of patients with active pulmonary TB. Chest (2010) 137:122-8. doi:10.1378/ chest.09-0903

54. Gröschel MI, Sayes F, Simeone R, Majlessi L, Brosch R. ESX secretion systems: mycobacterial evolution to counter host immunity. Nat Rev Microbiol (2016) 14:677-91. doi:10.1038/nrmicro.2016.131

55. Gröschel MI, Sayes F, Shin SJ, Frigui W, Pawlik A, Orgeur M, et al. Recombinant BCG expressing ESX-1 of Mycobacterium marinum combines low virulence with cytosolic immune signaling and improved TB protection. Cell Rep (2017) 18:2752-65. doi:10.1016/j.celrep.2017.02.057

56. Kupz A, Zedler U, Stäber M, Perdomo C, Dorhoi A, Brosch R, et al. ESAT6-dependent cytosolic pattern recognition drives noncognate tuberculosis control in vivo. J Clin Invest (2016) 126:2109-22. doi:10.1172/JCI84978

57. Ravn P, Boesen H, Pedersen BK, Andersen P. Human T cell responses induced by vaccination with Mycobacterium bovis bacillus Calmette-Guérin. J Immunol (1997) 158:1949-55.

58. Marchant A, Goetghebuer T, Ota MO, Wolfe I, Ceesay SJ, De Groote D, et al. Newborns develop a Th1-type immune response to Mycobacterium bovis bacillus Calmette-Guérin vaccination. J Immunol (1999) 163:2249-55.

59. Averill LE, Cavallo U, Wallis RS, Boom WH, Bona M, Mincek M, et al. Screening of a cosmid library of Mycobacterium bovis BCG in Mycobacterium smegmatis for novel T-cell stimulatory antigens. Res Microbiol (1993) 144:349-62. doi:10.1016/0923-2508(93)90192-5

60. Smith SM, Brookes R, Klein MR, Malin AS, Lukey PT, King AS, et al. Human CD8+ CTL specific for the mycobacterial major secreted antigen 85A. J Immunol (2000) 165:7088-95. doi:10.4049/jimmunol.165.12.7088

61. Turner J, Dockrell HM. Stimulation of human peripheral blood mononuclear cells with live Mycobacterium bovis BCG activates cytolytic CD8+ $\mathrm{T}$ cells in vitro. Immunology (1996) 87:339-42. doi:10.1046/j.1365-2567. 1996.512590.x

62. Grode L, Seiler P, Baumann S, Hess J, Brinkmann V, Nasser Eddine A, et al. Increased vaccine efficacy against tuberculosis of recombinant Mycobacterium bovis bacille Calmette-Guérin mutants that secrete listeriolysin. J Clin Invest (2005) 115:2472-9. doi:10.1172/JCI24617

63. Desel C, Dorhoi A, Bandermann S, Grode L, Eisele B, Kaufmann SHE. Recombinant BCG $\Delta$ ureC hly+ induces superior protection over parental BCG by stimulating a balanced combination of type 1 and type 17 cytokine responses. J Infect Dis (2011) 204:1573-84. doi:10.1093/infdis/jir592

64. Loxton AG, Knaul JK, Grode L, Gutschmidt A, Meller C, Eisele B, et al. Safety and immunogenicity of the recombinant Mycobacterium bovis BCG vaccine 
VPM1002 in HIV-unexposed newborn infants in South Africa. Clin Vaccine Immunol (2017) 24:e439-416. doi:10.1128/CVI.00439-16

65. Hoft DF, Blazevic A, Selimovic A, Turan A, Tennant J, Abate G, et al. Safety and immunogenicity of the recombinant BCG vaccine AERAS- 422 in healthy BCG-naïve adults: a randomized, active-controlled, first-in-human phase 1 trial. EBioMedicine (2016) 7:278-86. doi:10.1016/j.ebiom.2016.04.010

66. Hoft DF, Blazevic A, Stanley J, Landry B, Sizemore D, Kpamegan E, et al. A recombinant adenovirus expressing immunodominant TB antigens can significantly enhance BCG-induced human immunity. Vaccine (2012) 30:2098-108. doi:10.1016/j.vaccine.2012.01.048

67. Gideon HP, Phuah J, Myers AJ, Bryson BD, Rodgers MA, Coleman MT, et al. Variability in tuberculosis granuloma $\mathrm{T}$ cell responses exists, but a balance of pro- and anti-inflammatory cytokines is associated with sterilization. PLoS Pathog (2015) 11:e1004603. doi:10.1371/journal.ppat.1004603

68. Gopal R, Monin L, Slight S, Uche U, Blanchard E, Fallert Junecko BA, et al. Unexpected role for IL-17 in protective immunity against hypervirulent Mycobacterium tuberculosis HN878 infection. PLoS Pathog (2014) 10:e1004099. doi:10.1371/journal.ppat.1004099

69. Aguilo N, Alvarez-Arguedas S, Uranga S, Marinova D, Monzón M, Badiola J, et al. Pulmonary but not subcutaneous delivery of BCG vaccine confers protection to tuberculosis-susceptible mice by an interleukin 17-dependent mechanism. J Infect Dis (2016) 213:831-9. doi:10.1093/infdis/jiv503

70. Cruz A, Torrado E, Carmona J, Fraga AG, Costa P, Rodrigues F, et al. BCG vaccination-induced long-lasting control of Mycobacterium tuberculosis correlates with the accumulation of a novel population of CD4+IL-17+TNF+IL-2+ T cells. Vaccine (2015) 33:85-91. doi:10.1016/j.vaccine.2014.11.013

71. Smith SG, Zelmer A, Blitz R, Fletcher HA, Dockrell HM. Polyfunctional CD4 T-cells correlate with in vitro mycobacterial growth inhibition following Mycobacterium bovis BCG-vaccination of infants. Vaccine (2016) 34:5298-305. doi:10.1016/j.vaccine.2016.09.002

72. Chatterjee S, Dwivedi VP, Singh Y, Siddiqui I, Sharma P, Van Kaer L, et al. Early secreted antigen ESAT-6 of Mycobacterium tuberculosis promotes protective Thelper 17 cell responses in a toll-like receptor-2-dependent manner. PLoS Pathog (2011) 7:e1002378. doi:10.1371/journal.ppat.1002378

73. Joosten SA, van Meijgaarden KE, Del Nonno F, Baiocchini A, Petrone L, Vanini V, et al. Patients with tuberculosis have a dysfunctional circulating B-cell compartment, which normalizes following successful treatment. PLoS Pathog (2016) 12:e1005687. doi:10.1371/journal.ppat.1005687

74. Lu LL, Chung AW, Rosebrock TR, Ghebremichael M, Yu WH, Grace PS, et al. A functional role for antibodies in tuberculosis. Cell (2016) 167:1-26. doi:10.1016/j.cell.2016.08.072

75. Sebina I, Cliff JM, Smith SG, Nogaro S, Webb EL, Riley EM, et al. Long-lived memory B-cell responses following BCG vaccination. PLoS One (2012) 7:e51381. doi:10.1371/journal.pone.0051381

76. Valentini D, Rao M, Rane L, Rahman S, Axelsson-Robertson R, Heuchel R, et al. Peptide microarray-based characterization of antibody responses to host proteins after bacille Calmette-Guérin vaccination. Int J Infect Dis (2017) 56:140-54. doi:10.1016/j.ijid.2017.01.027

77. Fletcher HA, Snowden MA, Landry B, Rida W, Satti I, Harris SA, et al. T-cell activation is an immune correlate of risk in BCG vaccinated infants. Nat Commun (2016) 7:11290. doi:10.1038/ncomms11290

78. Sebina I, Biraro IA, Dockrell HM, Elliott AM, Cose S. Circulating B-lymphocytes as potential biomarkers of tuberculosis infection activity. PLoS One (2014) 9:e106796. doi:10.1371/journal.pone.0106796

79. Vogelzang A, Perdomo C, Zedler U, Kuhlmann S, Hurwitz R, Gengenbacher $\mathrm{M}$, et al. Central memory CD4+ $\mathrm{T}$ cells are responsible for the recombinant bacillus Calmette-Guérin $\Delta$ ureC::hly vaccine's superior protection against tuberculosis. J Infect Dis (2014) 210:1928-37. doi:10.1093/ infdis/jiu347

80. Kaveh DA, Garcia-Pelayo MC, Hogarth PJ. Persistent BCG bacilli perpetuate CD4 T effector memory and optimal protection against tuberculosis. Vaccine (2014) 32:6911-8. doi:10.1016/j.vaccine.2014.10.041

81. Armbruster C, Junker W, Vetter N, Jaksch G. Disseminated bacille CalmetteGuérin infection in an AIDS patient 30 years after BCG vaccination. J Infect Dis (1990) 162:1216. doi:10.1093/infdis/162.5.1216

82. Heldwein KA, Liang MD, Andresen TK, Thomas KE, Marty AM, Cuesta N, et al. TLR2 and TLR4 serve distinct roles in the host immune response against Mycobacterium bovis BCG. JLeukoc Biol (2003) 74:277-86. doi:10.1189/ jlb.0103026
83. Sendide K, Reiner NE, Lee JSI, Bourgoin S, Talal A, Hmama Z. Cross-talk between CD14 and complement receptor 3 promotes phagocytosis of mycobacteria: regulation by phosphatidylinositol 3-kinase and cytohesin-1. J Immunol (2005) 174:4210-9. doi:10.4049/jimmunol.174.7.4210

84. Kleinnijenhuis J, Quintin J, Preijers F, Joosten LAB, Ifrim DC, Saeed S, et al. Bacille Calmette-Guerin induces NOD2-dependent nonspecific protection from reinfection via epigenetic reprogramming of monocytes. Proc Natl Acad Sci U S A (2012) 109:17537-42. doi:10.1073/pnas.1202870109

85. Levy O, Wynn JL. A prime time for trained immunity: innate immune memory in newborns and infants. Neonatology (2014) 105:136-41. doi:10.1159/ 000356035

86. Kleinnijenhuis J, Quintin J, Preijers F, Joosten LAB, Jacobs C, Xavier RJ, et al. BCG-induced trained immunity in NK cells: role for non-specific protection to infection. Clin Immunol (2014) 155:213-9. doi:10.1016/j.clim.2014.10.005

87. Cheng S-C, Quintin J, Cramer RA, Shepardson KM, Saeed S, Kumar V, et al. mTOR- and HIF-1 $\alpha$-mediated aerobic glycolysis as metabolic basis for trained immunity. Science (2014) 345:1250684. doi:10.1126/science.1250684

88. Arts RJW, Blok BA, Aaby P, Joosten LAB, de Jong D, van der Meer JWM, et al. Long-term in vitro and in vivo effects of $\gamma$-irradiated BCG on innate and adaptive immunity. JLeukoc Biol (2015) 98:995-1001. doi:10.1189/ jlb.4MA0215-059R

89. Jensen KJ, Larsen N, Biering-Sørensen S, Andersen A, Eriksen HB, Monteiro I, et al. Heterologous immunological effects of early BCG vaccination in lowbirth weight infants in Guinea-Bissau: a randomized-controlled trial. J Infect Dis (2014) 211:956-67. doi:10.1093/infdis/jiu508

90. Smith SG, Kleinnijenhuis J, Netea MG, Dockrell HM. Whole blood profiling of bacillus Calmette-Guérin-induced trained innate immunity in infants identifies epidermal growth factor, IL-6, platelet-derived growth factor-AB/BB, and natural killer cell activation. Front Immunol (2017) 8:698. doi:10.3389/fimmu.2017.00644

91. Black GF, Weir RE, Floyd S, Bliss L, Warndorff DK, Crampin AC, et al. BCG-induced increase in interferon-gamma response to mycobacterial antigens and efficacy of BCG vaccination in Malawi and the UK: two randomised controlled studies. Lancet (2002) 359:1393-401. doi:10.1016/ S0140-6736(02)08353-8

92. Lalor MK, Ben-Smith A, Gorak-Stolinska P, Weir RE, Floyd S, Blitz R, et al. Population differences in immune responses to bacille Calmette-Guérin vaccination in infancy. J Infect Dis (2009) 199:795-800. doi:10.1086/597069

93. Lalor MK, Floyd S, Gorak-Stolinska P, Ben-Smith A, Weir RE, Smith SG, et al. BCG vaccination induces different cytokine profiles following infant BCG vaccination in the UK and Malawi. J Infect Dis (2011) 204:1075-85. doi:10.1093/infdis/jir515

94. Herzmann C, Sotgiu G, Schaberg T, Ernst M, Stenger S, Lange C, et al. Childhood BCG vaccination does not influence control of Mycobacterium tuberculosis growth by human bronchoalveolar lavage cells. Tuberculosis (Edinb) (2015) 95:321-7. doi:10.1016/j.tube.2015.02.044

95. Jensen KJ, Karkov HS, Lund N, Andersen A, Eriksen HB, Barbosa AG, et al. The immunological effects of oral polio vaccine provided with BCG vaccine at birth: a randomised trial. Vaccine (2014) 32:5949-56. doi:10.1016/j. vaccine.2014.08.062

96. Jones CE, Hesseling AC, Tena-Coki NG, Scriba TJ, Chegou NN, Kidd M, et al. The impact of HIV exposure and maternal Mycobacterium tuberculosis infection on infant immune responses to bacille Calmette-Guérin vaccination. AIDS (2015) 29:155-65. doi:10.1097/QAD.0000000000000536

97. Mawa PA, Nkurunungi G, Egesa M, Webb EL, Smith SG, Kizindo R, et al. The impact of maternal infection with Mycobacterium tuberculosis on the infant response to bacille Calmette-Guérin immunization. Philos Trans $R$ Soc Lond B Biol Sci (2015) 370:20140137. doi:10.1098/rstb.2014.0137

98. Mawa PA, Webb EL, Filali-Mouhim A, Nkurunungi G, Sekaly R-P, Lule SA, et al. Maternal BCG scar is associated with increased infant proinflammatory immune responses. Vaccine (2017) 35:273-82. doi:10.1016/j. vaccine.2016.11.079

99. Elliott AM, Mawa PA, Webb EL, Nampijja M, Lyadda N, Bukusuba J, et al. Effects of maternal and infant co-infections, and of maternal immunisation, on the infant response to BCG and tetanus immunisation. Vaccine (2010) 29:247-55. doi:10.1016/j.vaccine.2010.10.047

100. Webb EL, Mawa PA, Ndibazza J, Kizito D, Namatovu A, Kyosiimire-Lugemwa J, et al. Effect of single-dose anthelmintic treatment during pregnancy on an infant's response to immunisation and on susceptibility to infectious diseases 
in infancy: a randomised, double-blind, placebo-controlled trial. Lancet (2011) 377:52-62. doi:10.1016/S0140-6736(10)61457-2

101. Appay V, Dunbar PR, Callan M, Klenerman P, Gillespie GMA, Papagno L, et al. Memory CD8+ T cells vary in differentiation phenotype in different persistent virus infections. Nat Med (2002) 8:379-85. doi:10.1038/ nm0402-379

102. Bello C, Whittle H. Cytomegalovirus infection in Gambian mothers and their babies. J Clin Pathol (1991) 44:366-9. doi:10.1136/jcp.44.5.366

103. Miles DJC, van der Sande M, Jeffries D, Kaye S, Ismaili J, Ojuola O, et al. Cytomegalovirus infection in Gambian infants leads to profound CD8 T-cell differentiation. J Virol (2007) 81:5766-76. doi:10.1128/JVI.00052-07

104. Kampmann B, Jones CE. Factors influencing innate immunity and vaccine responses in infancy. Philos Trans R Soc Lond B Biol Sci (2015) 370:20140148. doi:10.1098/rstb.2014.0148

105. Miles DJC, van der Sande M, Crozier S, Ojuola O, Palmero MS, Sanneh M, et al. Effects of antenatal and postnatal environments on $\mathrm{CD} 4 \mathrm{~T}$-cell responses to Mycobacterium bovis BCG in healthy infants in the Gambia. Clin Vaccine Immunol (2008) 15:995-1002. doi:10.1128/CVI.00037-08

106. Burl S, Adetifa UJ, Cox M, Touray E, Ota MO, Marchant A, et al. Delaying bacillus Calmette-Guérin vaccination from birth to 4 1/2 months of age reduces postvaccination Th1 and IL-17 responses but leads to comparable mycobacterial responses at 9 months of age. J Immunol (2010) 185:2620-8. doi:10.4049/jimmunol.1000552

107. Kagina BMN, Abel B, Bowmaker M, Scriba TJ, Gelderbloem S, Smit E, et al. Delaying BCG vaccination from birth to 10 weeks of age may result in an enhanced memory CD4 T cell response. Vaccine (2009) 27:5488-95. doi:10.1016/j.vaccine.2009.06.103

108. Lutwama F, Kagina BM, Wajja A, Waiswa F, Mansoor N, Kirimunda S, et al. Distinct T-cell responses when BCG vaccination is delayed from birth to 6 weeks of age in Ugandan infants. J Infect Dis (2014) 209:887-97. doi:10.1093/ infdis/jit570

109. Ritz N, Casalaz D, Donath S, Tebruegge M, Dutta B, Connell TG, et al. Comparable CD4 and CD8 $\mathrm{T}$ cell responses and cytokine release after at-birth and delayed BCG immunisation in infants born in Australia. Vaccine (2016) 34:4132-9. doi:10.1016/j.vaccine.2016.06.077

110. Tchakoute CT, Hesseling AC, Kidzeru EB, Gamieldien H, Passmore J-AS, Jones CE, et al. Delaying BCG vaccination until 8 weeks of age results in robust BCG-specific T-cell responses in HIV-exposed infants. J Infect Dis (2015) 211:338-46. doi:10.1093/infdis/jiu434

111. Kagina BMN, Abel B, Scriba TJ, Hughes EJ, Keyser A, Soares A, et al. Specific $\mathrm{T}$ cell frequency and cytokine expression profile do not correlate with protection against tuberculosis after bacillus Calmette-Guérin vaccination of newborns. Am J Respir Crit Care Med (2010) 182:1073-9. doi:10.1164/ rccm.201003-0334OC

112. Fletcher HA, Filali-Mouhim A, Nemes E, Hawkridge A, Keyser A, Njikan S, et al. Human newborn bacille Calmette-Guérin vaccination and risk of tuberculosis disease: a case-control study. BMC Med (2016) 14:76. doi:10.1186/ s12916-016-0617-3
113. Tameris MD, Hatherill M, Landry BS, Scriba TJ, Snowden MA, Lockhart S, et al. Safety and efficacy of MVA85A, a new tuberculosis vaccine, in infants previously vaccinated with BCG: a randomised, placebo-controlled phase $2 \mathrm{~b}$ trial. Lancet (2013) 381:1021-8. doi:10.1016/S0140-6736(13)60177-4

114. Cliff JM, Lee J-S, Constantinou N, Cho J-E, Clark TG, Ronacher K, et al. Distinct phases of blood gene expression pattern through tuberculosis treatment reflect modulation of the humoral immune response. J Infect Dis (2013) 207:18-29. doi:10.1093/infdis/jis499

115. Worku S, Hoft DF. In vitro measurement of protective mycobacterial immunity: antigen-specific expansion of T cells capable of inhibiting intracellular growth of bacille Calmette-Guérin. Clin Infect Dis (2000) 30(Suppl 3): S257-61. doi:10.1086/313887

116. Fletcher HA, Tanner R, Wallis RS, Meyer J, Manjaly Z-R, Harris S, et al. Inhibition of mycobacterial growth in vitro following primary but not secondary vaccination with Mycobacterium bovis BCG. Clin Vaccine Immunol (2013) 20:1683-9. doi:10.1128/CVI.00427-13

117. Blazevic A, Xia M, Turan A, Tennant J, Hoft DF. Pilot studies of a human BCG challenge model. Tuberculosis (Edinb) (2017) 105:108-12. doi:10.1016/j. tube.2017.05.001

118. Harris SA, Meyer J, Satti I, Marsay L, Poulton ID, Tanner R, et al. Evaluation of a human BCG challenge model to assess antimycobacterial immunity induced by BCG and a candidate tuberculosis vaccine, MVA85A, alone and in combination. J Infect Dis (2014) 209:1259-68. doi:10.1093/infdis/ jit647

119. Matsumiya M, Satti I, Chomka A, Harris SA, Stockdale L, Meyer J, et al. Gene expression and cytokine profile correlate with mycobacterial growth in a human BCG challenge model. J Infect Dis (2015) 211:1499-509. doi:10.1093/ infdis/jiu615

120. Boer MC, Prins C, van Meijgaarden KE, van Dissel JT, Ottenhoff THM, Joosten SA. Mycobacterium bovis BCG vaccination induces divergent proinflammatory or regulatory $\mathrm{T}$ cell responses in adults. Clin Vaccine Immunol (2015) 22:778-88. doi:10.1128/CVI.00162-15

121. Newell EW, Sigal N, Bendall SC, Nolan GP, Davis MM. Cytometry by timeof-flight shows combinatorial cytokine expression and virus-specific cell niches within a continuum of CD8+ T cell phenotypes. Immunity (2012) 36:142-52. doi:10.1016/j.immuni.2012.01.002

Conflict of Interest Statement: The authors declare that the research was conducted in the absence of any commercial or financial relationships that could be construed as a potential conflict of interest.

Copyright $\odot 2017$ Dockrell and Smith. This is an open-access article distributed under the terms of the Creative Commons Attribution License (CC BY). The use, distribution or reproduction in other forums is permitted, provided the original author(s) or licensor are credited and that the original publication in this journal is cited, in accordance with accepted academic practice. No use, distribution or reproduction is permitted which does not comply with these terms. 